\title{
High-Glucose Induced Protective Effect against Hypoxic Injury Is Associated with Maintenance of Mitochondrial Membrane Potential
}

\author{
Min Hwa KIM, Yi-Sook JUNG*, Chang-Hyun MoON*, Soo Hwan LEE*, \\ Eun Joo BAIK*, and Chang-Kiu MOON \\ Laboratory of Hygienic Chemistry, College of Pharmacy, Seoul National University, Seoul,151-742 Korea; and * Department \\ of Physiology, School of Medicine, Ajou University, Suwon, 442-749 Korea
}

\begin{abstract}
Our previous report has showed that the treatment of $48 \mathrm{~h}$ with $22 \mathrm{mM}$ glucose prevents hypoxia-induced cardiac cell death. In the present study, we investigated whether high glucose affects the mitochondrial death pathway during hypoxia, and if it does, what relates to the high glucose induced cardioprotection. Heart-derived $\mathrm{H} 9 \mathrm{c} 2$ cells were incubated in low $(5.5 \mathrm{mM})$ or high $(22 \mathrm{mM})$ glucose medium for $48 \mathrm{~h}$, then transferred to a normoxic or hypoxic condition. The hypoxia-induced reduction of mitochondrial redox potential, assessed by MTT assay, was inhibited in high glucose treated cells. The mitochondrial membrane potential was significantly decreased by hypoxia in low glucose treated cells, but not in high glucose treated cells. The hypoxia-induced cytoplasmic accumulation of cytochrome c, released from the mitochondria, was blocked by a treatment of high glucose. High glu-
\end{abstract}

cose did not induce the expression of an antiapoptotic protein $\mathrm{Bcl}-2$, nor did it reduce a proapoptotic protein Bax, but it did inhibit a hypoxia-induced downregulation of Bcl-2. The cellular ATP contents were not changed by the treatment of high glucose for $48 \mathrm{~h}$, and the hypoxia-induced decline of intracellular ATP level was observed in high glucose treated cells and in low glucose. A glycolytic inhibitor, 2-deoxyglucose, did not reverse the high glucose induced reduction of $\mathrm{LDH}$ release. The elevation of $[R O S]_{i}$ induced by hypoxia was inhibited in high glucose treated cells. These results suggest that high glucose induced cardioprotection may be accounted for in part by the preservation of MMP and the maintenance of a basal level of [ROS $]_{i}$ during hypoxia. [The Japanese Journal of Physiology 53: 451-459, 2003]

Key words: $\quad$ high glucose, cardioprotection, MMP, cytochrome c, Bcl-2, ROS.

Mitochondria have recently received a lot of attention for their roles in the determination of life and death in cardiac myocytes and a variety of other cells [1-4]. The function of mitochondria is impaired by various stimuli, including ischemia, resulting in an increase of calcium in cytosol and/or in mitochondria and subsequent cell death [1,2]. This mitochondrial death pathway has been demonstrated to involve mitochondrial permeability transition (MPT), thereby causing a disruption of mitochondrial membrane potential (MMP, $\Delta \Psi_{\mathrm{m}}$ ), ROS production, and release of apoptogenic factors such as cytochrome c and Apaf-1 (apoptosis protease activating factor-1) [3, 5, 6]. These factors further induce the activation of downstream caspases, which causes nuclear condensation, cytoplasmic fragmentation leading to ultimate cell death $[6,7]$. Bcl-2 has been known to play an antiapoptotic role by preventing cytochrome $\mathrm{c}$ release

Received on November 5, 2003; accepted on November 25, 2003

Correspondence should be addressed to: Chang-Kiu Moon, Laboratory of Hygienic Chemistry, College of Pharmacy, Seoul National University, Seoul, 151-742 Korea. Tel: +82-2-880-7843, Fax: +82-2-884-4580, E-mail: moonck@snu.ac.kr

Abbreviations: MPT, mitochondrial permeability transition; MMP, mitochondrial membrane potential; ROS, reactive oxygen species; MTT, 3(4,5-dimethylthiazol-2-yl)-2,5-diphenyl tetrazolium bromide; Apaf-1, apoptosis protease activating factor-1; 2-DOG, 2-deoxyglucose; NM, normoxia; HX, hypoxia. 
from mitochondria through the stabilization of membrane integrity and the inhibition of the opening of the MPT pore (or megachannel), whereas proapoptotic member Bax promotes cytochrome $\mathrm{c}$ release through the MPT pore opening $[8,9]$.

Although the incidence of cardiac complications and mortality after myocardial infarction is higher in diabetic patients than in nondiabetics [10], there is substantial evidence about the beneficial effect of diabetes against ischemic injury. In hyperglycemic animal models, an improvement in functional recovery after ischemia and resistance against ischemic injury has been reported [11-14].

Our previous report has demonstrated that high glucose treatment could produce cytoprotective effect against hypoxic injury in heart-derived $\mathrm{H} 9 \mathrm{c} 2$ cells via PKC activation [15]. Recently, Seo et al. [4] has reported that high glucose prevents rat cortical neuron from hypoxia-induced cell death through the enhancement of mitochondrial membrane potential. Hitherto, however, there is no knowledge about the effect of high glucose on the mitochondrial death pathway in cardiac myocytes. Thus, in this study we investigated whether high glucose induced cardioprotection against hypoxia involves the improvement of the mitochondrial dysfunction in terms of the loss of $\Delta \Psi_{\mathrm{m}}$, cytochrome $\mathrm{c}$ release and ROS generation.

\section{METHODS}

Cell culture. H9c2 cells were purchased from the American Type Culture Collection (ATCC, USA) and maintained in Dulbecco's modified Eagle's medium (DMEM) containing $5.5 \mathrm{mM}$ glucose supplemented with $10 \%$ fetal bovine serum and $1 \%$ penicillin/streptomycin. For experiments, cells were further maintained for $48 \mathrm{~h}$ in DMEM containing low glucose $(5.5 \mathrm{mM})$ or high glucose $(22 \mathrm{mM})$. The duration of $48 \mathrm{~h}$ was chosen from the result that the protective effect of $22 \mathrm{mM}$ glucose was shown at the treatment duration of at least $24 \mathrm{~h}$ and the maximum protective effect was shown at $48 \mathrm{~h}$ (data not shown). For hypoxic challenges, $\mathrm{H} 9 \mathrm{c} 2$ cells were transferred into an anoxic chamber $(<1 \%$ oxygen, ThermoForma, USA) maintained at $37^{\circ} \mathrm{C}$ with a humidified atmosphere of $5 \% \mathrm{CO}_{2}, 10 \% \mathrm{H}_{2}$, and $85 \% \mathrm{~N}_{2}$. In the anoxic chamber, a culture medium was replaced with serum-free, glucose-free DMEM saturated with $\mathrm{N}_{2}$ gas for $1 \mathrm{~h}$ prior to use. A normoxic incubation of cells in serum-free DMEM was conducted in a $5 \%$ $\mathrm{CO}_{2}$ incubator at $37^{\circ} \mathrm{C}$.

MTT assay. The mitochondrial dehydrogenase activity that cleaves 3-(4,5-dimethylthiazol-2-yl)-2,5- diphenyl tetrazolium bromide (MTT) was used to determine mitochondrial redox potential in a quantitative colorimetric assay [16]. H9c2 cells were incubated with $100 \mu \mathrm{g} / \mathrm{ml}$ MTT in PBS for $2 \mathrm{~h}$ at $37^{\circ} \mathrm{C}$. Formazan product was dissolved in solubilization solution containing $5 \%$ acetic acid, $5 \% 1 \mathrm{~N}-\mathrm{HCl}, 50 \%$ $\mathrm{N}, \mathrm{N}$-dimethylformamide, and 20\% SDS (pH 4.7), and absorbance was recorded at $570 \mathrm{~nm}$.

Measurement of mitochondrial membrane potential. H9c2 cells grown on a glass-bottom dish were loaded with $5 \mu \mathrm{M}$ rhodamine 123 (Molecular Probes, Eugene, OR, USA), a fluorescent dye indicating mitochondrial membrane potential, in HEPESbuffered control salt solution (HCSS) containing $120 \mathrm{mM} \mathrm{NaCl}, 5 \mathrm{mM} \mathrm{KCl}, 1.6 \mathrm{mM} \mathrm{MgCl}_{2}, 2.3 \mathrm{mM}$ $\mathrm{CaCl}_{2}, 15 \mathrm{mM}$ glucose, $20 \mathrm{mM}$ HEPES, and $10 \mathrm{mM}$ $\mathrm{NaOH}$. The cells were incubated for $10 \mathrm{~min}$ at $37^{\circ} \mathrm{C}$ and washed three times with HCSS, and the fluorescence signal $(E x=480 \mathrm{~nm} ; E m=520 \mathrm{~nm})$ of rhodamine 123 was analyzed on the stage of a Nikon Diaphot inverted microscope equipped with a $100 \mathrm{~W}$ xenon lamp. The background fluorescence signal of rhodamine 123 was determined on a glass-bottom dish without cells and subtracted from rhodamine 123 signals obtained in $\mathrm{H} 9 \mathrm{c} 2$ cells. All images were analyzed by using a Quanticell 700 system (Applied Imaging).

Cytochrome c release. $\mathrm{H} 9 \mathrm{c} 2$ cells were washed twice with ice-cold PBS and collected by centrifugation at $200 \times \mathrm{g}$ for $10 \mathrm{~min}$ at $4^{\circ} \mathrm{C}$. The pellets were then responded in extraction buffer containing $220 \mathrm{mM}$ mannitol, $68 \mathrm{mM}$ sucrose, $20 \mathrm{mM}$ HEPES (pH 7.4), $50 \mathrm{mM} \mathrm{KCl}, 5 \mathrm{mM}$ EGTA, $2 \mathrm{mM} \mathrm{MgCl}_{2}, 1 \mathrm{mM}$ EDTA, and $1 \mathrm{mM}$ DTT, as well as protease inhibitors. The cells were homogenized for 40 strokes in a glass homogenizer. The homogenates were then centrifuged at $14,000 \times g$ for $30 \mathrm{~s}$ to remove pellet nuclei, and the supernatants were centrifuged once more at $200,000 \times g$ for $30 \mathrm{~min}$. The resulting supernatants as cytosolic fraction and pellets as mitochondrial fraction were subjected to electrophoresis on $12.5 \%$ acrylamide gels, then transferred to a PVDF membrane (Millipore, Bedford, MD, USA). After being blocked in 5\% nonfat dry milk for $90 \mathrm{~min}$, the blots were incubated overnight with antibody to cytochrome c (Santa Cruz). Following washout three times with Trisbuffered saline containing $0.05 \%$ tween 20 , the membrane was incubated with antirabbit immunoglobulin goat antibody conjugated with alkaline phosphatase ( $1: 3,000$ dilution, Santa Cruz) for $4 \mathrm{~h}$, and washed out two times with TBS-T and the last time with alkaline phosphate buffer $(\mathrm{pH}$ 9.5). The cytochrome $\mathrm{c}$ band was visualized by using the NBT/BCIP method. 
The contamination of the cytosolic fraction with mitochondria was checked with the mitochondrial protein COX IV.

Bcl-2 and Bax expression. The cell culture medium was aspirated, and the cells were washed twice with ice-cold PBS. Added to the cells was $200 \mu \mathrm{l} /$ well of hypotonic HEPES buffer $(10 \mathrm{mM}$ HEPES, $5 \mathrm{mM} \mathrm{MgCl}_{2}, 40 \mathrm{mM} \mathrm{KCl}, 2 \mathrm{mM}$ EDTA, $1 \mathrm{mM}$ PMSF, $10 \mu \mathrm{g} / \mathrm{ml}$ aprotinin, $10 \mu \mathrm{g} / \mathrm{ml}$ leupeptin, $1 \mathrm{mM}$ sodium orthovanadate, $\mathrm{pH}$ 7.4). After $30 \mathrm{~min}$, the cells were aspirated repeatedly with a 25 gage needle and centrifuged at $200 \times g$ for $10 \mathrm{~min}$ to remove nuclei. The supernatants were further centrifuged at $10,000 \times g$ for $15 \mathrm{~min}$ to obtain heavy membrane fraction containing mitochondria. They were collected and subjected to electrophoresis on $12.5 \%$ acrylamide gels, then transferred to PVDF membrane (Millipore). After being blocked in 5\% nonfat dry milk for $90 \mathrm{~min}$, the blots were incubated $2 \mathrm{~h}$ with antibody to Bcl-2 and $\operatorname{Bax}(1: 100$ dilution, Santa Cruze). Following washout three times with TBS containing $0.05 \%$ tween 20, the membrane was incubated with antirabbit immunoglobulin goat antibody conjugated with alkaline phosphatase (1:3,000 dilution, Santa Cruze) for $4 \mathrm{~h}$, and washed out two times with TBS-T and the last time with alkaline phosphate buffer ( $\mathrm{pH}$ 9.5). Bcl2 and Bax were visualized by using NBT/BCIP.

Measurement of intracellular ATP content. The intracellular ATP content of cells was measured with the ATP luminescent assay kit (Molecular Probes). The cells were lysed directly in lysis buffer, and the lysate was assayed according to the manufacturer's instructions. Light emitted was measured with a luminometer (TD-30/20, TURNER DESIGNS). The ATP content was calculated by comparison with a standard curve derived from known concentrations of ATP, ranging from 0.01 to $10 \mathrm{pmol}$.

LDH release. Overall cell injury was assessed by measuring the amount of lactate dehydrogenase (LDH) released into the medium $10 \mathrm{~h}$ after hypoxia as previously described [4]. The percent of LDH release was calculated from the maximum LDH release $(100 \%)$ induced by adding $0.1 \%$ triton X-100.

Measurement of intracellular ROS generation. H9c2 cells grown on a glass-bottom dish were loaded with $5 \mu \mathrm{M}$ dihydrodichlorofluorescein diacetate (DHDCF-DA; Molecular Probes) plus 2\% Pluronic F-127 in HEPES-buffered control salt solution (HCSS). The cells were incubated for $20 \mathrm{~min}$ at $37^{\circ} \mathrm{C}$ and washed three times with HCSS, and the fluorescence signal of DCF $(E x=490 \mathrm{~nm} ; E m=510 \mathrm{~nm})$, an oxidation product of DHDCF-DA by free radicals, was analyzed on the stage of a Nikon Diaphot inverted microscope equipped with a $100 \mathrm{~W}$ xenon lamp. To minimize background signal caused by the direct oxidation of DHDCF-DA by illumination at $490 \mathrm{~nm}$, the intracellular levels of ROS were analyzed within $3 \mathrm{sec}$ after illumination by using a Quanticell 700 system (Applied Imaging).

Statistic. All data were compared by using Student's $t$-test for unpaired observations between two groups. The $p$ value of $<0.05$ was considered significant.

\section{RESULTS}

\section{Effect of high glucose on mitochondrial redox potential during hypoxia}

MTT reductase activity represents mitochondrial redox potential and cellular viability. Mitochondrial redox potential in low glucose treated cells fell to below $90 \%$ of normoxia control level within $2 \mathrm{~h}$ of hypoxia (Fig. 1). It remained in a steady state at $85 \%$ for the next $4 \mathrm{~h}$, then further decreased. But in high glucose treated cells, mitochondrial redox potential was significantly higher than in low glucose control cells and did not decrease within $10 \mathrm{~h}$ of hypoxia.

Impairment in mitochondrial redox activity (Fig. 1) occurred before any sign of cell death was observed (data not shown), indicating that the decrease in metabolism and the consequent fall in energy production was not a result of the loss of live cells, but instead was due to a metabolic impairment within a population that was still viable.

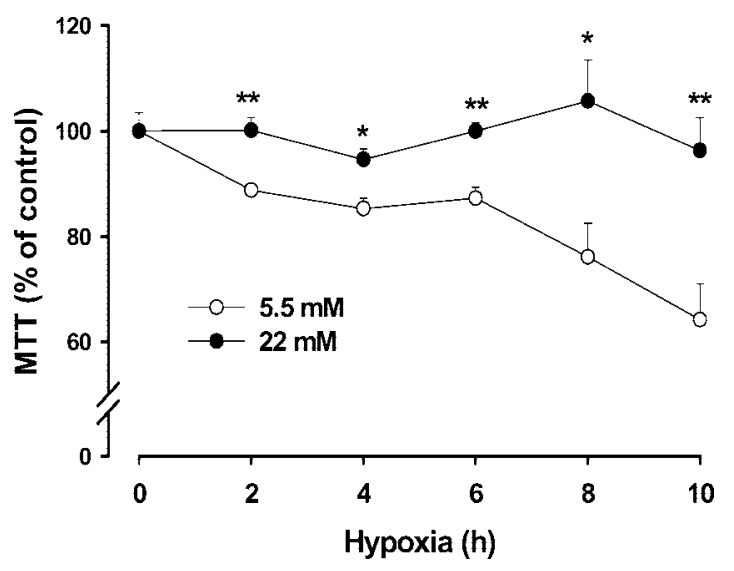

Fig. 1. Effect of high glucose on mitochondrial redox potential during hypoxia. The cells were incubated in low $(5.5 \mathrm{~mm})$ or high $(22 \mathrm{~mm})$ glucose medium for $48 \mathrm{~h}$, then transferred to hypoxic condition. Mitochondrial dehydrogenase activity was assayed by a reduction of MTT at 0, 2, 4, 6, 8, and $10 \mathrm{~h}$ after exposure to hypoxia. Open circle, $5.5 \mathrm{~mm}$ glucose; closed circle, $22 \mathrm{~mm}$ glucose. Data represent mean \pm SEM $(n=6)$. Significant difference from relevant control group (treated with $5.5 \mathrm{mM}$ glucose) at * $p<0.05$, ${ }^{\star *} p<0.01$, using Student's $t$-test. 


\section{Effect of high glucose on mitochondrial mem- brane potential during hypoxia}

Because the loss of mitochondrial membrane potential can be sufficient to activate cardiac cell death $[3,5,17]$, we hypothesized that the cytoprotective effect of high glucose against hypoxic injury might be related to the effect of high glucose on the level of mitochondrial membrane potential. MMP was examined by using the positively charged and lipophilic rhodamine 123 that permeates into the negatively charged mitochondria and therefore reflects the mitochondrial membrane potential [18]. To measure the fluorescence signal of rhodamine 123 on the stage of an inverted microscope without the interference of plastic culture ware, we should culture cells by using a glass-bottom dish and on the dish; the cells will be easily detached under hypoxic condition. Therefore we could not measure the precise MMP beyond $4 \mathrm{~h}$. On the other hand, a loss of MMP lagged slightly behind changes in MTT reductase activity, and intracellular ATP content was reported previously [3]. The fluorescence signal of rhodamine 123 in cells cultured in high glucose medium (108.3 \pm 3.6$)$ was not significantly different at normoxic condition compared to cells cultured in low glucose medium (101.3 \pm 1.3 ) (Fig. 2A, B). After $4 \mathrm{~h}$ of hypoxia, the fluorescence signal in cells cultured in low glucose media was significantly decreased (cold

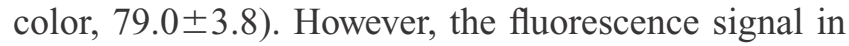
cells cultured in high glucose medium was not altered $(101.3 \pm 7.0)$. These results demonstrate that mitochondrial membrane potential in high glucose treated cells is preserved during hypoxia.

\section{Effect of high glucose on hypoxia-induced cytochrome $\mathrm{c}$ release from mitochondria}

During the apoptotic process, mitochondria undergo major changes in membrane integrity that concern both the inner and the outer membranes, leading to a disruption of the inner membrane potential and the release of intermembrane proteins through the outer membrane. Cytochrome c, a mitochondrial intermembrane protein, release into the cytosol at the late phase of apoptotic cell death after mitochondrial membrane function is lost [19]. We therefore investigated the effects of high glucose on the hypoxia-induced cytochrome c release into cytosol. Cytochrome $\mathrm{c}$ was detected in low glucose treated cytosolic fraction after $6 \mathrm{~h}$ of hypoxia, but not in high glucose treated cytosolic fraction (Fig. 3). Hypoxia-induced cytochrome c release was completely blocked by the treatment of high glucose.

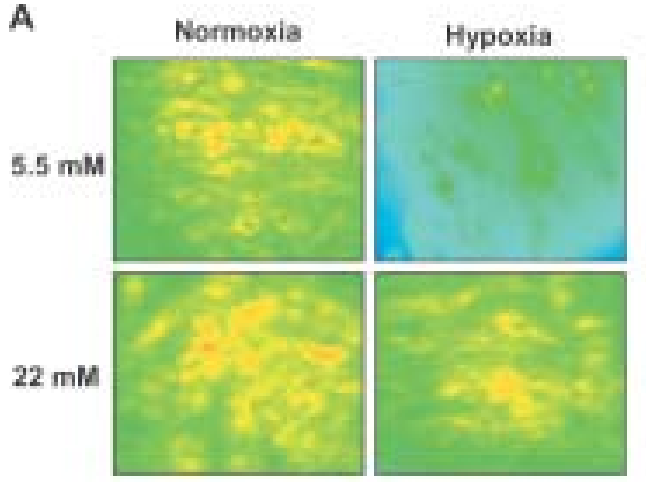

B

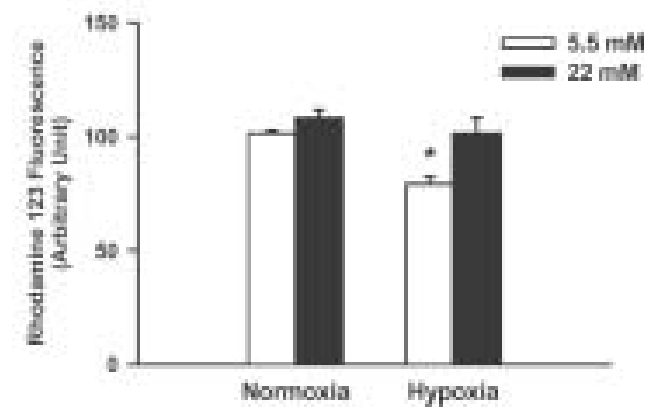

Fig. 2. Effect of high glucose on mitochondrial membrane potential during hypoxia. The cells were incubated in low $(5.5 \mathrm{~mm})$ or high $(22 \mathrm{~mm})$ glucose medium for $48 \mathrm{~h}$, then transferred to normoxic or hypoxic condition for $4 \mathrm{~h}$. A: Fluorescence photomicrographs (stained with rhodamine 123) of cells after incubation in normoxic or hypoxic condition. The more warm the color, the higher MMP. B: Mitochondrial membrane potential was analyzed by measuring the fluorescence intensity of rhodamine 123. Open bar, $5.5 \mathrm{~mm}$ glucose; closed bar, $22 \mathrm{~mm}$ glucose. Data represent mean \pm SEM $(n=4)$. Significant difference from $5.5 \mathrm{mM}$ glucose treated cells in normoxia at * $p<0.05$, using Student's t-test.

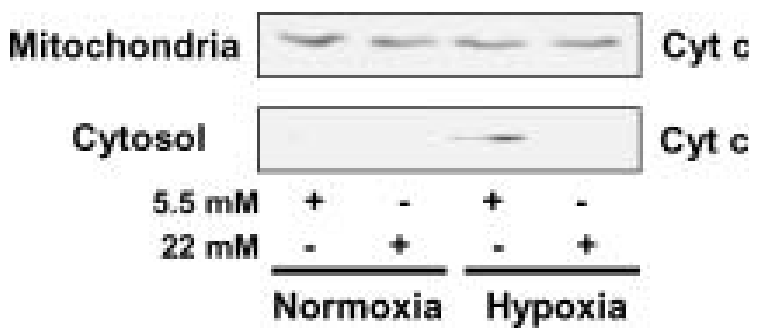

Fig. 3. Subcellular localization of cytochrome $\mathrm{c}$ in low or high glucose treated myocytes following exposure to normoxic or hypoxic condition. The cells were incubated in low (5.5 mM) or high (22 mM) glucose medium for $48 \mathrm{~h}$, then transferred to normoxic or hypoxic condition for $6 \mathrm{~h}$. The cytosolic and mitochondrial fractions of cells were separated. Western blotting for cytochrome c was performed as described in method. Similar results were obtained in three additional independent cell preparations. 


\section{Effect of high glucose on hypoxia-induced decline of Bcl-2}

The Bcl-2 family is well known as a key regulator of the apoptotic response through the modulation of cytochrome c release from mitochondria and intracellular ROS generation $[8,9,20,21]$. We examined the response of antiapoptotic Bcl-2 and proapoptotic Bax to high glucose leading to cardioprotection against hypoxia. The expression levels of $\mathrm{Bcl}-2$ and $\mathrm{Bax}$ were not altered by high glucose treatment for $48 \mathrm{~h}$ (Fig. 4). After $6 \mathrm{~h}$ of hypoxia, the level of Bax was not altered, but Bcl-2 expression was downregulated. Hypoxia-induced downregulation of Bcl-2 was blocked in high glucose treated cells.

\section{Effect of high glucose on ATP levels before and during hypoxia}

To test the possibility that the ATP production through the utilization of high glucose is responsible for high glucose induced protection, we measured the ATP contents of cells that were treated with low or high glucose for $48 \mathrm{~h}$ and cells that were exposed to hypoxia after treatment of low or high glucose for $48 \mathrm{~h}$.

The intracellular ATP contents during low or high glucose treatment were not significantly changed (Fig. 5A). During hypoxia, the cellular ATP levels were decreased within $6 \mathrm{~h}(5.5 \mathrm{mM}: 15 \pm 0.8 \rightarrow 2.2 \pm 0.6$, $22 \mathrm{mM}: 15 \pm 0.9 \rightarrow 4.3 \pm 1.6$ ), which ultimately declined to $<1 \%$ of control cells up to $8 \mathrm{~h}$ both in low and high glucose treated cells $(5.5 \mathrm{mM}: 0.1 \pm 1.5,22 \mathrm{mM}$ : $0.1 \pm 2.1)$ (Fig. 5B). These results reflect that high glucose does not act as an energy source and the absence of the glycolytic production of ATP.

\section{Effect of glycolytic inhibitor, 2-deoxyglucose on the high glucose induced protective effect against hypoxic cell death}

To confirm that high glucose induced protection was not due to ATP production through the glycolysis, the cells were incubated in low or high glucose medium with or without 2-deoxyglucose (1,3,5 mM), which is a glycolytic inhibitor, then transferred to hypoxic condition. 2-Deoxyglucose accumulates as 2deoxyglucose-6- $\mathrm{PO}_{4}$, which cannot be further metabolized by phosphohexose isomerase in the glycolytic pathway. Hypoxia-induced LDH release was dramatically inhibited in high glucose treated cells $(5.5 \mathrm{mM}$ : 65.3 \pm 2.8 ; $22 \mathrm{mM}: 28.1 \pm 1.2, p<0.01$ ) (Fig. 6). 2-Deoxyglucose did not reverse the high glucose-induced reduction of LDH release (2-DOG $1 \mathrm{mM}$ : 28.6 \pm 1.6 , $3 \mathrm{mM}: 21.7 \pm 1.8,5 \mathrm{mM}: 29.4 \pm 1.7)$.

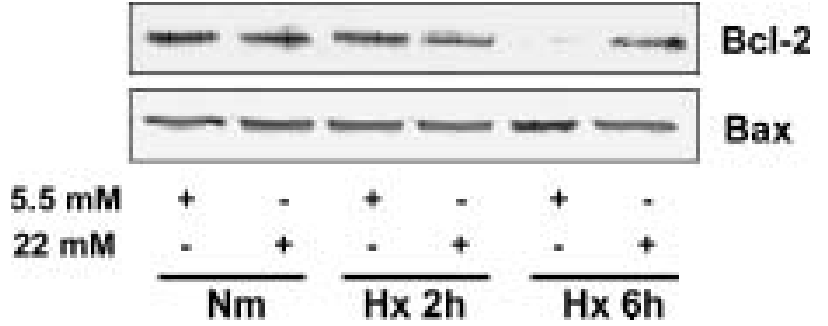

Fig. 4. Effect of high glucose on Bcl-2, Bax expression. The cells were incubated in low $(5.5 \mathrm{~mm})$ or high $(22 \mathrm{mM})$ glucose medium for $48 \mathrm{~h}$, then transferred to normoxic or hypoxic condition for $6 \mathrm{~h}$. Western blotting for Bcl2 and Bax were performed as described in method. Similar results were obtained in three additional independent cell preparations.

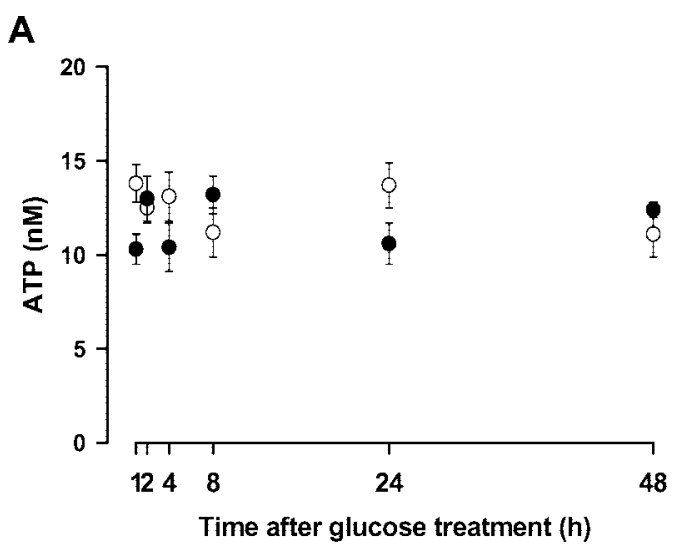

B

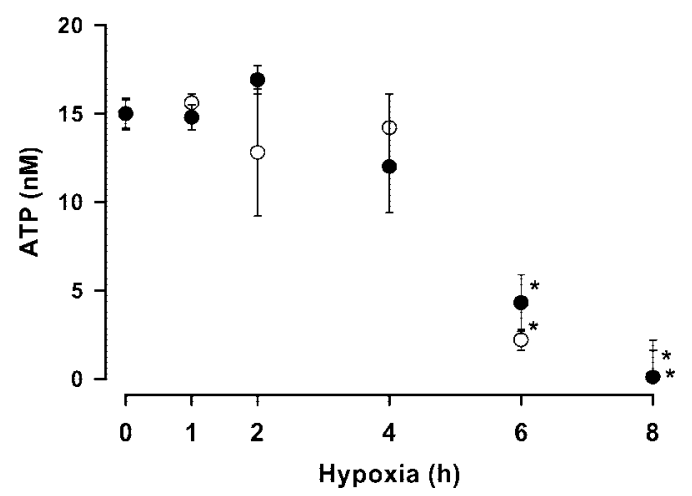

Fig. 5. Effect of high glucose on intracellular ATP content. The cells were incubated in low $(5.5 \mathrm{mM})$ or high $(22 \mathrm{~mm})$ glucose medium for $48 \mathrm{~h}$. A: ATP concentrations at 1, 2, 4, 8, 24, and $48 \mathrm{~h}$ after incubation were determined. B: After incubation in low or high glucose medium for $48 \mathrm{~h}$, the cells were transferred to hypoxic condition. ATP concentrations at 1, 2, 4, 6, and $8 \mathrm{~h}$ after hypoxia were determined. Open circle, $5.5 \mathrm{~mm}$ glucose; closed circle, $22 \mathrm{~mm}$ glucose. Data represent mean \pm SEM $(n=6)$. Significant difference from control at ${ }^{*} p<0.05$, using Student's $t$-test. Similar results were obtained in two additional independent myocyte preparations. 


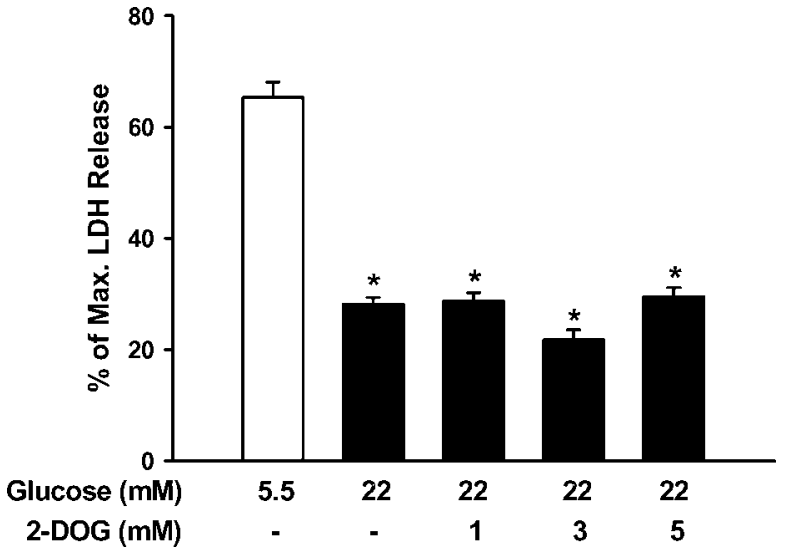

Fig. 6. Effect of glycolytic inhibitor on high glucoseinduced cardioprotection. The cells were incubated in low $(5.5 \mathrm{~mm})$ or high $(22 \mathrm{mM})$ glucose medium with or without glycolytic inhibitor, 2-deoxyglucose (2-DOG, 1, 3, $5 \mathrm{mM}$ ), for $48 \mathrm{~h}$, then transferred to hypoxic condition for $10 \mathrm{~h}$. The activity of lactate dehydrogenase released into medium was measured as described in method. Open bar, $5.5 \mathrm{~mm}$ glucose; closed bar, $22 \mathrm{mM}$ glucose. Data represent mean \pm SEM $(n=6)$. Significant difference from $5.5 \mathrm{mM}$ glucose control at ${ }^{*} p<0.01$, using Student's t-test.

\section{Effect of high glucose on ROS generation during hypoxia}

ROS includes superoxide anion, hydrogen peroxide, and hydroxyl radical and is known to play a central role in apoptotic death and in necrotic death [5]. During ischemia, increased ROS triggers mitochondrial dysfunction leading to cardiac cell death [17]. Therefore we examined the effect of high glucose on $[R O S]_{i}$ during hypoxia. The baseline levels of $[R O S]_{i}$ were similar between the low and high glucose treated cells at normoxia $(100 \pm 0.1,101.1 \pm 1.1$, respectively). After $4 \mathrm{~h}$ of hypoxia, $[\mathrm{ROS}]_{\mathrm{i}}$ was dramatically increased in low glucose treated control cells (warm color, 133.3 \pm 8.1$)$. Whereas $[\mathrm{ROS}]_{\mathrm{i}}$ in high glucose treated cells was not altered (97.1 \pm 5.0$)$ (Fig. 7A, B). For the same reason described above, we measured $[R O S]_{i}$ at $4 \mathrm{~h}$ after hypoxia. These results represent that high glucose absolutely inhibits the ROS generation induced by hypoxia in $\mathrm{H} 9 \mathrm{c} 2$ cells.

\section{DISCUSSION}

Following our previous report that the treatment of $22 \mathrm{mM}$ high glucose for $48 \mathrm{~h}$ conferred the H9c2 cells resistance to the hypoxic injury [14], this study has demonstrated that the mechanism of the high glucose induced cardioprotection involves the preservation of mitochondrial membrane potential and the inhibition of ROS generation during hypoxia.

Mitochondria are recognized as central regulators

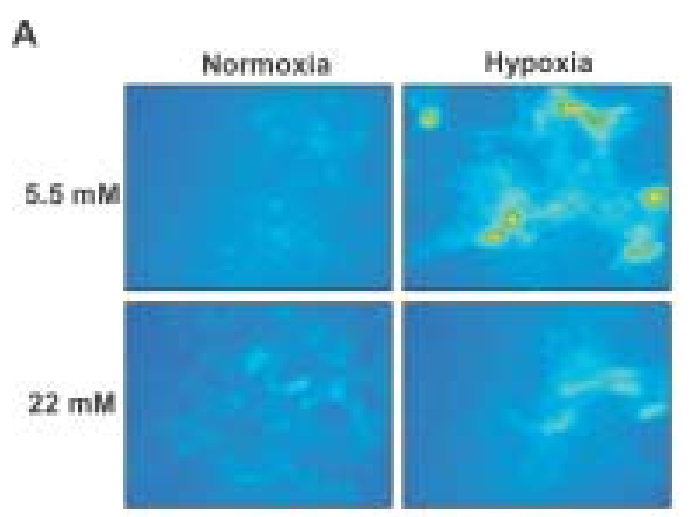

B

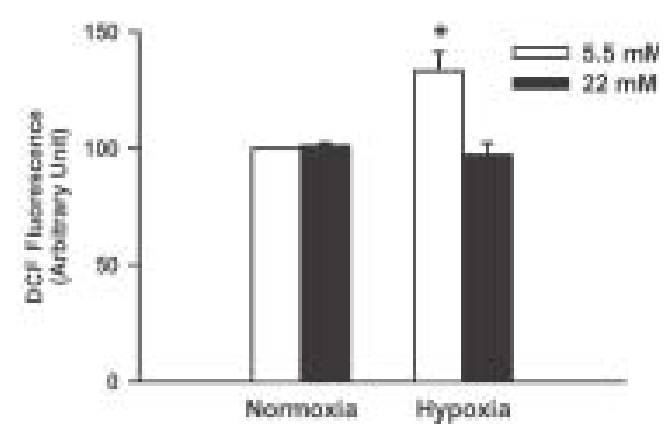

Fig. 7. Effect of high glucose on generation of reactive oxygen species during hypoxia. The cells were incubated in low $(5.5 \mathrm{~mm})$ or high $(22 \mathrm{mM})$ glucose medium for $48 \mathrm{~h}$, then transferred to normoxic or hypoxic condition for $4 \mathrm{~h}$. A: Fluorescence photomicrographs (stained with DHDCF-DA) of cells after incubation in normoxic or hypoxic condition. The more warm color, the higher concentration of ROS. B: ROS generation was analyzed by measuring the fluorescence intensity of oxidized DHDCF-DA. Open bar, $5.5 \mathrm{~mm}$ glucose; closed bar, $22 \mathrm{~mm}$ glucose. Data represent mean \pm SEM $(n=4)$. Significant difference from $5.5 \mathrm{mM}$ glucose-treated cells in normoxia at * $p<0.05$, using Student's t-test.

of life and death under various stresses in a variety of cells $[1,2,22]$. Cardiac mitochondria are highly vulnerable to injury induced by ischemia, which precipitates myocardial dysfunction in several disease conditions. In heart, mitochondrial dysfunction induced by hypoxia or other stimuli has been demonstrated to produce mitochondrial permeability transition (MPT), the disruption of mitochondrial membrane potential (MMP), and subsequent cytochrome c release, leading to lethal cell injury $[3,5,23]$. Therefore preserving the functional and structural integrity of mitochondria is considered a prerequisite for successful cardioprotection [24]. Indeed, several strategies that modulate mitochondrial function and ATP production have been considered $[25,26]$ to reduce myocardial injury and to improve cardiac function. We previously demonstrated that hyperglycemic rat heart [27] and high glu- 
cose treated cardiac cells [15] were less susceptible for ischemic injury. A recent report has demonstrated that the enhanced $\Delta \Psi_{\mathrm{m}}$ is responsible for the high glucose induced protective effect in neurons [4]. Since the investigation about the effect of high glucose on the mitochondrial dysfunction during hypoxia has not been done in cardiac cells, this study was performed by using heart-derived $\mathrm{H} 9 \mathrm{c} 2$ cells to investigate whether high glucose can affect hypoxia-induced mitochondrial dysfunction, in consideration of the mitochondrial membrane potential, cytochrome c release, Bcl-2/Bax expression, and ROS generation.

In this study, we found that high glucose significantly improved the hypoxia-induced decrease in the redox potential of mitochondria (Fig. 1), as assessed by the conversion of the tetrazolium dye MTT to its reduced form, a reaction mediated by mitochondrial reductase [16]. Furthermore, our results showed that $\mathrm{H} 9 \mathrm{c} 2$ cells exhibited a reduction of mitochondrial membrane potential after $4 \mathrm{~h}$ of hypoxia, and that the loss of mitochondrial membrane potential by hypoxia was reversed by pretreatment with high glucose (Fig. 2). Consistent with our results, other reports (or, another report) also proved that cardiac myocytes from hyperglycemic hearts were less prone to ischemia/ reperfusion-induced mitochondrial dysfunctions, such as a depolarization of $\Delta \Psi_{\mathrm{m}}$ [28].

It has been reported that cytochrome c release results from changes in mitochondrial membrane permeability after a loss of membrane potential $\left(\Delta \Psi_{\mathrm{m}}\right)$. Although cytochrome $\mathrm{c}$ release can precede and occur independently of decreased $\Delta \Psi_{\mathrm{m}}$, a dissipation of $\Delta \Psi_{\mathrm{m}}$ has often been sufficient for cytochrome c release to occur [29]. We therefore examined the effect of high glucose on cytochrome c release to cytosolic fraction and found that the hypoxia-induced appearance of cytochrome $\mathrm{c}$ in the cytosolic fraction of control cells was completely reduced in the cytosol of high glucose treated cells (Fig. 3). Our results showing the good correlation between the effects of glucose on mitochondrial membrane potential and cytochrome c release further support the hypothesis that mitochondrial membrane potential controls the permeability of membrane and regulates cytochrome c release [30].

Among intracellular apoptosis regulating proteins that have been reported, the Bcl-2 family plays a pivotal role in regulating the responses of cells to a wide variety of apoptotic signals [8,9]. Bcl-2 has been known to play antiapoptotic role by preventing cytochrome c release from mitochondria through the stabilization of membrane integrity and the inhibition of the opening of the MPT pore (or megachannel), whereas proapoptotic member Bax promotes cytochrome $\mathrm{c}$ release through the MPT pore opening $[8$, 9]. According to Schaffer [31], Bcl-2 overexpression has blocked cardiac cell death induced by chemical hypoxia. Recently, the balance between Bcl-2 and Bax has been regarded more important than Bcl-2 or Bax by itself. In ischemic preconditioning, the level of Bcl-2 expression was not altered, but proapoptotic protein Bax was downregulated [32]. During hypoxia in this study, the level of Bax was not altered, but Bcl2 expression was downregulated (Fig. 4). Although our study did not show the effect of high glucose itself on Bcl-2 upregulation or Bax downregulation, a hypoxia-induced reduction of Bcl-2 was prevented by high glucose treatment (Fig. 4) without affecting Bax expression. Therefore high glucose-induced inhibition of Bcl-2 reduction during hypoxia may be attributed to the stabilization of mitochondrial membrane potential and the prevention of cytochrome c release.

On the basis of the previous reports that ATP depletion during hypoxia causes mitochondrial dysfunction followed by cell death [33], and that hyperglycemia produces an increase in myocardial glucose uptake [34], we hypothesized that high glucose induced maintenance of mitochondrial function may be ascribed to the preservation of ATP production through increased glucose uptake and glycolysis. To examine this hypothesis, we investigated the effect of high glucose on ATP levels in intact cells before and after hypoxia. It is interesting that we found ATP levels in high glucose-treated $\mathrm{H} 9 \mathrm{c} 2$ cells remaining similar to those observed in control cells, and that the remarkable decline of ATP levels during hypoxia shown in control cells was not altered by pretreatment with high glucose throughout the course of hypoxia (Fig. 5). Consistent with our results, another study has demonstrated that the level of ATP was not increased, but remained unaltered under the condition of substantial increase in intracellular glucose concentration [35]. We further found that the glycolytic inhibitor, 2-deoxyglucose, did not reverse the high glucose induced protective effect against hypoxia-induced cell death (Fig. 6). From these results, it is suggested that the high glucose induced protective effect may not be attributed to an increase in ATP production through glycolysis, but to a blockade of death signaling a pathway somewhere near or upstream of the mitochondria. Our results further support the others that the feedback regulation of hexokinase, a rate-limiting enzyme in the glycolytic pathway, by glucose-6-phosphate, a product of hexokinase, may have an influence on the limitation of the overall glycolysis and ATP production in high glucose treated cells [35]. On the other 
hand, our findings are quite inconsistent with those of Malhotra et al. [7], who found that a $30 \mathrm{~min}$ treatment with high glucose protects cardiac cells from hypoxic injury through an increased glycolysis of extracellular glucose. The differences between the duration of glucose treatment $(48 \mathrm{~h}$ vs. $30 \mathrm{~min}$ ) and the cell type (H9c2 cells vs. primary cultures) may explain this discrepancy in terms of cellular energetics.

Mitochondria has long been known to play a role in the generation and processing of $[\mathrm{ROS}]_{\mathrm{i}}$, and that mitochondrial dysfunction can result in accumulation of $[R O S]_{i}$ leading to cell death $[5,36]$. In contrast, there is also increasing evidence that ROS is a major contributing factor on the mitochondrial dysfunction through mitochondrial permeability transition $[1,22]$, suggesting the a causative relationship between ROS generation and mitochondrial dysfunction is still controversial [22]. Indeed, it has been demonstrated that during hypoxia, ROS has been explosively produced at the respiratory chain of the mitochondrial membrane, causing the loss of mitochondrial function in cardiomyocytes [36], and that antioxidant could protect the mitochondrial function against ischemiareperfusion [37]. Recently, it has been postulated that ROS may play a dual role in apoptosis, either as activators of permeability transition or as a consequence of this transition, depending on the death stimulus [1]. In the present study, ROS generation was elevated in a hypoxic condition in $\mathrm{H} 9 \mathrm{c} 2$ cells, and this elevation was blocked by high glucose treatment (Fig. 7).

In summary, we found a good correlation between glucose-induced inhibitory effects on the ROS generation and on the mitochondrial dysfunction during hypoxia, though this study did not address the causative relationship between these effects of high glucose. From our results, it is suggested that the improvement of mitochondrial dysfunction and the inhibition of ROS generation during hypoxia may be, at least in part, involved in the high glucose induced cardioprotection against hypoxic injury in heart-derived $\mathrm{H} 9 \mathrm{c} 2$ cells.

This work was supported by grants from the Ministry of Health and Welfare (00-PJ2-PG1-CD02-0018) and the Research Institute of Pharmaceutical Sciences, College of Pharmacy, Seoul National University.

\section{REFERENCES}

1. Green DR and Reed JC: Mitochondria and apoptosis. Science 281: 1309-1312, 1998

2. Regula KM, Ens K, and Kirshenbaum LA: Mitochondria-assisted cell suicide: a license to kill. J Mol Cell Cardiol 35: 559-567, 2003
3. Bialik S, Cryns VL, Drincic A, Miyata S, Wollowick AL, Srinivasan A, and Kitsis RN: The mitochondrial apoptotic pathway is activated by serum and glucose deprivation in cardiac myocytes. Circ Res 85: 403-414, 1999

4. Seo SY, Kim EY, Kim H, and Gwag BJ: Neuroprotective effect of high glucose against NMDA, free radical, and oxygen-glucose deprivation through enhanced mitochondrial potentials. J Neurosci 19: 8849-8855, 1999

5. Zorov DB, Filburn CR, Klotz LO, Zweier JL, and Sollott SJ: Reactive oxygen species (ROS)-induced ROS release: a new phenomenon accompanying induction of the mitochondrial permeability transition in cardiac myocytes. J Exp Med 192: 1001-1014, 2000

6. Moissac D, Gurevich RM, Zheng H, Singal PK, and Kirshenbaum LA: Caspase activation and mitochondrial cytochrome $\mathrm{c}$ release during hypoxia-mediated apoptosis of adult ventricular myocytes. J Mol Cell Cardiol 32: 53-63, 2000

7. Malhotra R and Brosius FC: Glucose uptake and glycolysis reduce hypoxia-induced apoptosis in cultured neonatal rat cardiac myocytes. J Biol Chem 274: 12567-12575, 1999

8. Misao J, Hayakawa Y, Ohno M, Kato S, Fujiwara T, Fujiwara $\mathrm{H}$ : Expression of bcl-2 protein, an inhibitor of apoptosis, and Bax, an accelerator of apoptosis, in ventricular myocytes of human hearts with myocardial infarction. Circulation 94: 1506-1512, 1996

9. Cook SA, Sugden PH, and Clerk Angela: Regulation of Bcl-2 family proteins during development and in response to oxidative stress in cardiac myocytes: association with changes in mitochondrial membrane potential. Circ Res 85: 940-949, 1999

10. Partamian JO and Bradley RF: Acute myocardial infarction in 258 cases of diabetes. N Engl J Med 273: 455-461, 1965

11. Tani M and Neeley JR: Hearts from diabetic rats are more resistant to in vitro ischemia: possible role of altered $\mathrm{Ca}^{2+}$ metabolism. Circ Res 62: 931-940, 1988

12. Liu Y, Thornton JD, Cohen MV, Downey JM, and Schaffer SW: Streptozotocin-induced non-insulin-dependent diabetes protects the heart from infarction. Circulation 88: 1273-1278, 1993

13. Feuvary D and Lopaschuk GD: Controversies on the sensitivity of the diabetic heart to ischemic injury: the sensitivity of the diabetic heart to ischemic injury is decreased. Cardiovasc Res 34: 113-120, 1997

14. Hadour G, Ferrera R, Sebbag L, Forrat R, Delaye J, and Lorgeril M: Improved myocardial tolerance to ischemia in the diabetic rabbit. J Mol Cell Cardiol 30: 1869-1875, 1998

15. Moon $\mathrm{CH}$, Jung $\mathrm{YS}$, Kim MH, Park RM, Lee $\mathrm{SH}$, and Baik EJ: Protein kinase $\mathrm{C}$ inhibitors attenuate protective effect of high glucose against hypoxic injury in $\mathrm{H} 9 \mathrm{c} 2$ cardiac cells. Jpn J Physiol 50: 645-649, 2000

16. Denizot F and Lang R: Rapid colorimetric assay for cell growth and survival: modifications to the tetrazolium dye procedure giving improved sensitivity and reliability. J Immunol Mehtods 89: 271-277, 1986

17. Levraut J, Iwase H, Shao ZH, Hoek TLV, and Schumacker PY: Cell death during ischemia: relationship to mitochondrial depolarization and ROS generation. Am J Physiol Heart Circ Physiol 284: H549-H558, 2003 
18. Emaus RK, Grunwald R, and Lemasters JJ: Rhodamine 123 as a probe of transmembrane potential in isolated rat-liver mitochondria: spectral and metabolic properties. Biochim Biophys Acta 23: 436-448, 1986

19. Cai J, Yang J, and Jones DP: Mitochondrial control of apoptosis: the role of cytochrome c. Biochim Biophys Acta 1366: 139-149, 1998

20. Kluck RM, Bossy-Wetzel E, Green DR, and Newmeyer DD: The release of cytochrome $c$ from mitochondria: a primary site for $\mathrm{Bcl}-2$ regulation of apoptosis. Science 275: 1132-1136, 1997

21. Narita M, Shimizu S, Ito T, Chittendon T, Lutz RJ, Matsuda $\mathrm{H}$, and Tsujimoto $\mathrm{Y}$ : Bax interacts with the permeability transition pore to induce permeability transition and cytochrome c release in isolated mitochondria. Proc Natl Acad Sci USA 95: 14681-14686, 1998

22. Kroemer G and Reed JC: Mitochondrial control of cell death. Nat Med 6: 513-519, 2000

23. Dzeja PP, Redfield MM, Burnett JC, and Terzic A: Mitochondria:gateway for cytoprotection. Circ Res 89: 744746, 2001

24. Luft R: Thedevelopment of mitochondrial medicine. Proc Natl Acad Sci USA 91: 8731-8738, 1994

25. Holmuhamedov EL, Ozcan C, Jahangir A, and Terzic A: Restoration of $\mathrm{Ca}^{2+}$-inhibited oxidative phosphorylation in cardiac mitochondria by mitochondrial $\mathrm{Ca}^{2+}$ unloading. Mol Cell Biochem 220: 135-140, 2001

26. Jo SH, Son MK, Koh HJ, Lee SM, Song IH, Kim YO, Lee YS, Jeong KS, Kim WB, Park JW, Song BJ, and Huhe TL: Control of mitochondrial redox balance and cellular defense against oxidative damage by mitochondrial $\mathrm{NADP}^{+}$-dependent isocitrate dehydrogenase. J Biol Chem 276: 16168-16176, 2001

27. Moon CH, Jung YS, Lee SH, and Baik EJ: Protein kinase $\mathrm{C}$ inhibitors abolish the increased resistance of diabetic rat heart to ischemia-refusion injury. Jpn $J$ Physiol 49: 409-415, 1999

28. Oliveira PJ, Rolo AP, Seica R, Sardao V, Monteiro P, Goncalves L, Providencia L, Palmeira CM, Santos MS, and Moreno AJ: Impact of diabetes on induction of the mitochondrial permeability transition. Rev Port Cardiol 21: 759-766, 2002
29. Hakem R, Hakem A, Duncan GS, Henderson JT, Woo M, Soengas MS, Elia A, de la Pompa JL, Kagi D, Khoo W, Potter J, Yoshida R, Kaufman SA, Lowe SW, Penninger JM, Mak TW: Differential requirement for caspases-9 in apoptotic pathways in vivo. Cell 94: 339352, 1998

30. lijima T, Mishima T, Tohyama M, Akagawa K, Iwao Y: Mitochondrial membrane potential and intracellular ATP content after transient experimental ischemia in the cultured hippocampal neuron. Neurochem Int 43: 263-269, 2003

31. Schaffer SW, Croft CB, and Solodushko V: Cardioprotective effect of chronic hyperglycemia: effect on hypoxia-induced apoptosis and necrosis. Am J Physiol Heart Circ Physiol 278: H1948-H1954, 2000

32. Nakamura M, Wang NP, Zhao ZQ, Wilcox JN, Thourani V, Guyton RA, and Vinten-Johansen J: Preconditioning decreases Bax expression, PMN accumulation and apoptosis in reperfused rat heart. Cardiovasc Res 45: 661-670, 2000

33. Chen SJ, Bradley ME, and Lee TC: Chemical hypoxia triggers apoptosis of cultured neonatal rat cardiac myocytes: modulation by calcium-regulated proteases an protein kinases. Mol Cell Biochem 178: 141-149, 1998

34. Hall JL, Henderson J, Hernandez LA, and Stanley WC: Hyperglycemia causes an increase in myocardial interstitial glucose and glucose uptake during ischemia in swine. Metabolism 45: 542-549, 1996

35. Manchester J, Kong X, Nerbonne J, Lowry $\mathrm{OH}$, and Lawrence JC Jr: Glucose transport and phosphorylation in single cardiac myocytes: rate-limiting steps in glucose metabolism. Am J Physiol 266: E326-E331, 1994

36. Duranteau J, Chandel NS, Kulisz A, Shao Z, and Schumacker $P$ : Intracellular signaling by reactive oxygen species during hypoxia in cardiomyocytes. J Biol Chem 273: 11619-11624, 1998

37. Crestanello JA, Doliba NM, Doliba NM, Babsky AM, Niborii K, Osbakken MD, and Whitman GJR: Effect of Coenzyme Q10 supplement on mitochondrial function after myocardial ischemia reperfusion. J Surg Res 102: 221-228, 2002 